\title{
Can the Core Stability Training Influences Sprint and Jump Performances in Young Basketball Players?
}

\author{
Italo Sannicandro' ${ }^{1}$ Giacomo Cofano ${ }^{2}$, Andrea Piccinno ${ }^{2}$ \\ ${ }^{1}$ Department of Clinical and Experimental Medicine, University of Foggia, Foggia, Italy \\ ${ }^{2}$ Strength and Conditioning Coach, Foggia, Italy \\ Email: italo.sannicandro@unifg.it
}

How to cite this paper: Sannicandro, I., Cofano, G., \& Piccinno, A. (2020). Can the Core Stability Training Influences Sprint and Jump Performances in Young Basketball Players? Advances in Physical Education, 10, 196-206.

https://doi.org/10.4236/ape.2020.103017

Received: May 12, 2020

Accepted: July 29, 2020

Published: July 30, 2020

Copyright $\odot 2020$ by author(s) and Scientific Research Publishing Inc. This work is licensed under the Creative Commons Attribution International License (CC BY 4.0).

http://creativecommons.org/licenses/by/4.0/

\section{(c) (i) Open Access}

\begin{abstract}
The core is the center of the functional kinetic chain providing the proximal stability for the distal mobility and function of the limbs. The study aims to verify the effects of an integrative core stability training on jump and sprint performance in young basketball players. Young basketball players were involved in the study ( $\mathrm{n}=42,16$ female, 26 male) whose age, stature and weight were respectively (average $\pm \mathrm{ds}$ ) $8.22 \pm 0.4$ years, $118.2 \pm 3.7 \mathrm{~cm}$ and $28.8 \pm$ $4.9 \mathrm{~kg}$ and was randomly divided in Training Group (TG, $\mathrm{n}=24,10 \mathrm{~F}, 14 \mathrm{M}$ ) and Control Group (CG, $\mathrm{n}=18,6 \mathrm{~F}, 12 \mathrm{M}$ ). The training program was monitored for 4 weeks ( 8 sessions, twice a week and lasting 1 hour each during the usual sports activity; in addition to the usual technical and sport-specific exercises, the TG introduced only 4 core stability exercises in the warm-up). The results revealed a change in test scores across the two time periods for TG in the left limb Side hop $(p<0.026)$, in the right limb side hop $(p<$ $0.001)$, in the left limb 6 meter timed hop $(p<0.0005)$, in the right limb 6 meter timed hop $(p<0.0005)$, in the vertical jump $(p<0.002)$, in the 10 meters sprint $(p<0.0005)$ and in the $10 \times 5$ meters test $(p<0.001)$. The CG highlighted differences statistically significant only in the 10 meters sprint $(p<$ $0.05)$. The study confirms the need to hypothesize in youth sport supplementary sessions intended for strength training, as the literature has already suggested for several years.
\end{abstract}

\section{Keywords}

Core Stability, Sprint, Jump

\section{Introduction}

The discussion about the real utility of core stability exercises in sport, today, is 
very current (Heneghan et al., 2020; Clark et al., 2018; Wirth et al., 2017; Lago-Fuentes et al., 2018; Calatayud et al., 2015; Bliven \& Anderson, 2013) and it concerns both athletes and young people who practice sports (Sato \& Mokha, 2009; Räisänen et al., 2018; Lago-Fuentes et al., 2018; Prieske et al., 2015; Hutchinson et al., 2016; Wirth et al., 2017; Granacher et al., 2014; Liebenson, 2011).

The core is the center of the functional kinetic chain providing the proximal stability for the distal mobility and function of the limbs (Clark et al., 2018; Hutchinson et al., 2016; Granacher et al., 2014; Ozmen, 2016; Calatayud et al., 2015; Bliven \& Anderson, 2013; Shinkle et al., 2012).

The core district strength is an important prerequisite for the practice of many sports, such as football, basketball, athletics jumping disciplines and others, and to carry out some everyday activities such as walking, climbing stairs, keep upright (Räisänen et al., 2018; Willardson, 2007; Akuthota et al., 2008; Sharrock et al., 2011; Jamison et al., 2012; Larsen et al., 2016; Sannicandro \& Cofano, 2017; Hibbs et al., 2008).

This district is very important from anatomical and functional point of view, in fact it has a twofold task, that is to check the stability of the lumbosacral tract, as well as act as a connection between the upper and lower appendicular tract: it acts as a functional unit capable of constituting a sorting joint of forces that must be conveyed from the lower appendicular tract to the upper one and vice versa (Akuthota et al., 2008; Shinkle et al., 2012; Bliven \& Anderson, 2013; Sannicandro \& Cofano, 2017).

To meet these two functional needs, within the training methodology, two different types of training are distinguished: the core stability tasks have the aim of increasing the control and stability of the lumbar spine; the core strength tasks aim to allow the transfer of high levels of muscle strength and power, activating local stabilizers and global mobilizing muscles (Larsen et al., 2016; Saeterbakken et al., 2011; Faries \& Greenwood, 2007; Sannicandro, 2014; Abenhaim et al., 2000; McGill, 2010; Liebenson, 2011).

Up to now, the literature has mainly focused on the description of the effectiveness of core stability exercises with sports subjects or with non-physically active adults, with particular reference to lower back pain and performance (McGill, 2010; Liebenson, 2011; Prieske et al., 2015) or to the effects of core training programs (Allen et al., 2014).

Conversely, in sports only few studies with teenagers practicing team sports have monitored the effects of a longer period, from 8 weeks to 6 months, of training on the strength of the core muscles, describing performance increases in the strength of the hip extensors and in performance jump with and without countermovement, as well as in sprint performance (Sannicandro \& Cofano 2017; Hoshikawa et al., 2013; Afyon, 2014; Durall et al., 2009).

In an interesting review that has studied the core-performance relationship, it is underlined how many researches that analyze the core training effects often include the integration with lower limb strength exercises (Reed et al., 2012).

Although it is evident the relationship between core control and single limb 
task control in prepubescent subjects (Hutchinson et al., 2016; Sasaki et al., 2019), only rarely and only recently the specific program effects have been investigated in youth basketball (Sannicandro \& Cofano, 2017).

The effects of only core stability exercises on jumping performance in young basketball players have recently been investigated.

Therefore, an open problem remains that of understanding the effects on motor performance only attributable to core stability exercises; in particular, especially in light of the sedentary lifestyles described in the developmental age (Colella et al., 2019; Weedon et al., 2018; Kuligowski et al., 2015; Wu et al., 2017), it must be clarified whether such types of exercises, which specifically encourage a very sensitive target district in this period (Kuligowski et al., 2015; Wu et al., 2017) could be advantageous for prepubescent subjects practicing sport.

Furthermore, due to the age and the motivation to practice sports of prepubescent subjects, the duration of the core training programs must be considered, which can only occupy a limited part of the session; for these reasons, this type of supplementary intervention can find space especially in the initial warm-up, as suggested for some time in the literature (Faigenbaum et al., 2005; Emery et al., 2015).

\section{Methods}

\subsection{Objective}

The study aims to verify the effects of an integrative core stability training on jump and sprint performance in young basketball players.

\subsection{Participants and Setting}

Young basketball players were involved in the study $(\mathrm{n}=42,16$ female, 26 male) whose age, stature and weight were respectively (average $\pm \mathrm{ds}$ ) $8.22 \pm 0.4$ years, $118.2 \pm 3.7 \mathrm{~cm}$ and $28.8 \pm 4.9 \mathrm{~kg}$.

The sample was randomly divided into Training Group (TG, $\mathrm{n}=24,10 \mathrm{~F}, 14$ $\mathrm{M}$ ) and Control Group (CG, $\mathrm{n}=18,6 \mathrm{~F}, 12 \mathrm{M}$ ). Only those who had more than $90 \%$ previous training compliance were included in the sample.

Their parents were informed of experimental procedures and provided written consent for their children to participate in the specific training; all participants were informed about the purpose of the study and the relevance of the proposed exercises. Additionally, the research design and procedures complied with the standards set out in the Declaration of Helsinki.

\subsection{Procedure}

The training program was monitored for 4 weeks (September 2019-October 2019 , in the first month of training season), with a total of 8 sessions twice a week and lasting 1 hour each during the usual sports activity; in addition to the usual technical and sport-specific exercises, the TG introduced 4 core stability exercises in the initial warm-up (Table 1). In the first 4 sessions the exercises were carried out in stable conditions (resting on the ground), while in the subsequent 4 sessions they were carried out using unstable surfaces (Table 2). 
Table 1 . The study design.

\begin{tabular}{ccccc}
\hline Group & Session 1 & Sessions 2 - & Sessions 6-9 & Session 10 \\
\hline GT & Test & $\begin{array}{c}\text { Core training } \\
\text { on stable condition } \\
\text { Specific sport drills }\end{array}$ & $\begin{array}{c}\text { Core training on } \\
\text { unstable surface/tools }\end{array}$ & Test \\
GC & Test & Specific sport drills & Test \\
\hline
\end{tabular}

Table 2 . The training group core stability program.

\begin{tabular}{|c|c|c|c|c|}
\hline $\begin{array}{l}\text { Core stability } \\
\text { program }\end{array}$ & $\begin{array}{c}\text { Test } \\
\text { T0 }\end{array}$ & $\begin{array}{c}4 \text { core stability training sessions } \\
\text { (stability conditions) }\end{array}$ & $\begin{array}{l}4 \text { core stability training sessions } \\
\text { (instability conditions) }\end{array}$ & $\begin{array}{c}\text { Test } \\
\mathrm{T} 1\end{array}$ \\
\hline & & & $\begin{array}{l}\text { Plank } 3 \times 10 \text { rip } \times 3 \text { sec with } \\
\text { upper limbs on unstable } \\
\text { surface/tools (Figure } 2 \text { ) }\end{array}$ & \\
\hline & & Plank $3 \times 10$ rip $\times 3 \mathrm{sec}$ & Static Side plank & \\
\hline & & Static Side plank & $2 \times 8$ rip $\times 3 \sec \times$ side with & \\
\hline & & $2 \times 8$ rip $\times 3 \sec \times$ side & lower limbs on unstable & \\
\hline & & Dynamic Side plank & surface/tools (Figure 3) & \\
\hline & & $3 \times 8$ rip $\times$ side & Dynamic Side plank & \\
\hline & & Mountain climb & $2 \times 8$ rip $\times$ side, with lower & \\
\hline & & $4 \times 6 \operatorname{rip} \times \operatorname{limb}$ (Figure 1$)$ & limbs on unstable surface/tools & \\
\hline & & & $\begin{array}{l}\text { Mountain climb } 4 \times 6 \text { rip } \times \text { limb, } \\
\text { with lower limbs on unstable } \\
\text { surface/tools }\end{array}$ & \\
\hline
\end{tabular}

The initial and final tests were carried out in the two lessons preceding and following the 8 established training sessions.

The CG only followed technical exercises and specific sports.

The monopodalic jumps were used to evaluate the strength of the individual lower limbs: side hop test, triple hop test and 6 meters timed hop test.

In particular, the first three tests return the jump values, respectively, to the left and right and long after 3 successive jumps on a single limb; the 6 meters timed hop test returns the time taken by the subject to reach the distance of 6 meters through monopodalic hops in a subsequent form.

A vertical jump (Abalakov) test was used to evaluate the explosive force in its vertical component.

The evaluation of acceleration was investigated by 10 metres sprint test with the use of photocells (Ergo test, Globus Italy); the Eurofit $10 \times 5 \mathrm{~m}$ shuttle test, the time of which was detected by photocells (Ergo test, Globus Italy), monitored the anaerobic capacity of the subjects in performing sprints with direction changes.

The descriptive statistics (mean and standard deviation) have been determined.

The T-test for paired data was used to check the intra-group differences (TG vs TG and CG vs CG) in T0 and T1 (Table 1). To verify the intergroup differences ( $\mathrm{TG}$ vs $\mathrm{CG}$ ), the $\mathrm{T}$-test for unpaired sample was used in T1. In both cases, the significance was set at $p<0.05$. Cohen's $d$ was used to verify the Effect Size indicating how large is the difference detected in the averages of TG vs CG at T1. As for the Effect Size, after calculating the $\delta$ index it is possible to convert it to a small effect size: $\leq 0.20$; medium: 0.50; large: $\geq 0.80$ (Cohen, 1992). 


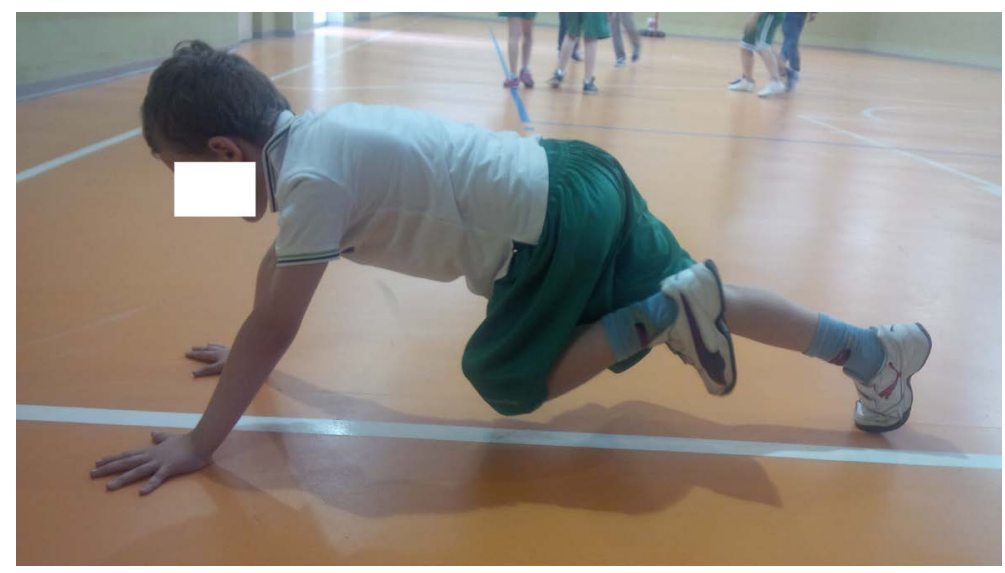

Figure 1. Mountain climber exercise.

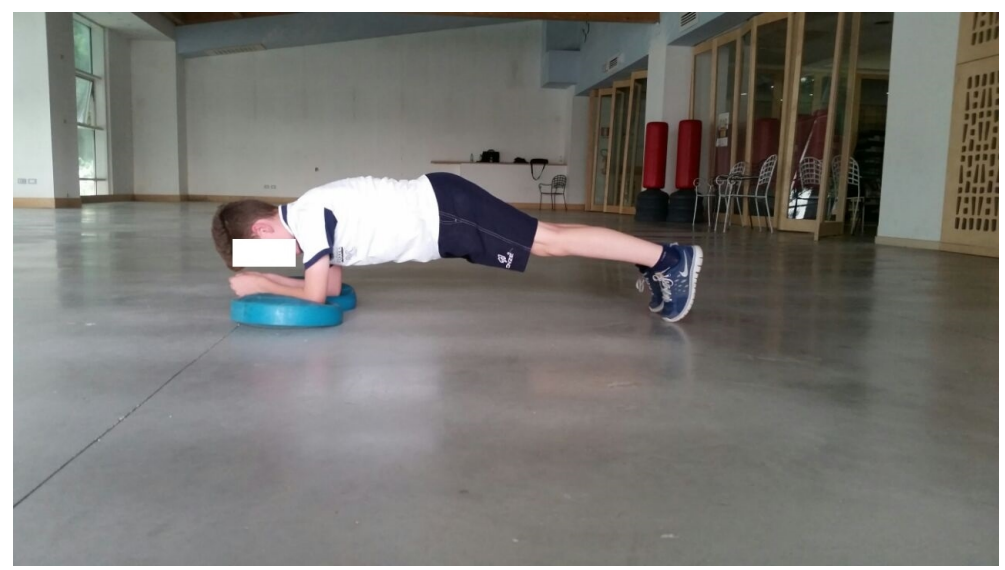

Figure 2. Plank on unstable surface/tool.

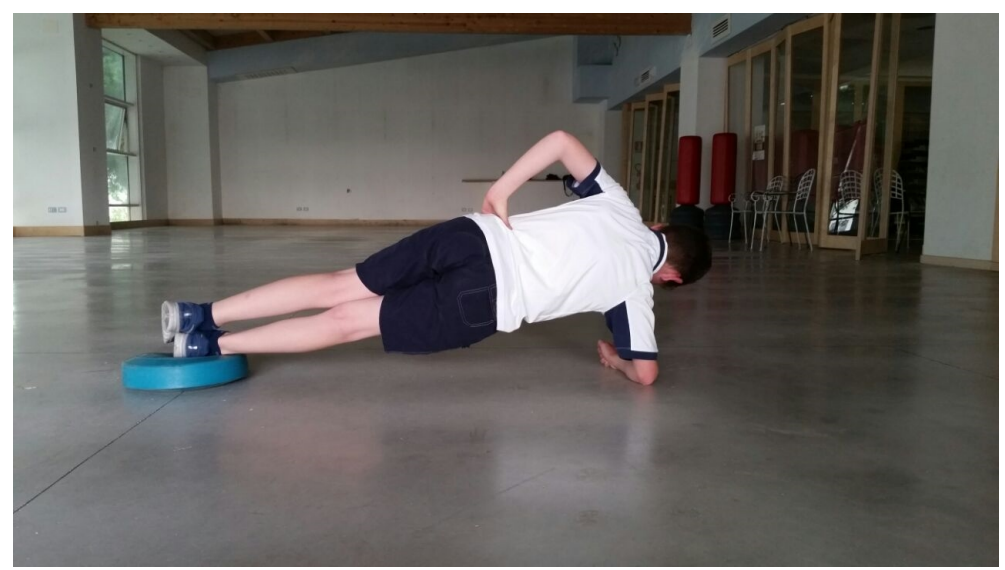

Figure 3. Side plank on unstable surface/tool.

\section{Results}

The results revealed a change in test scores across the two time periods (preintervention, post intervention) for TG in the left limb Side hop (37.80 \pm 6.327 $\mathrm{cm}$ vs $40.98 \pm 5.710 \mathrm{~cm}, p<0.026)$, in the right limb side hop $(36.88 \pm 5.6 \mathrm{~cm}$ vs $41.92 \pm 6.9 \mathrm{~cm}, p<0.001)$, in the left limb 6 meter timed hop $(5.65 \pm 0.55 \mathrm{sec}$ vs 
$4.28 \pm 0.96 \mathrm{sec}, p<0.0005)$, in the right limb 6 meter timed hop $(5.45 \pm 0.75 \mathrm{sec}$ vs $4.33 \pm 0.39 \mathrm{sec}, p<0.0005)$, in the vertical jump $(13.22 \pm 3.6 \mathrm{~cm}$ vs $16.11 \pm 3.1$ $\mathrm{cm}, p<0.002)$, the 10 meters sprint $(4.647 \pm 1.09 \mathrm{sec}$ vs $3.887 \pm 1.11 \mathrm{sec}, p<$ $0.0005)$ and in the $10 \times 5$ meters test $(33.66 \pm 3.15 \mathrm{sec}$ vs $31.51 \pm 3.86 \mathrm{sec}, p<$ $0.001)$. The differences in triple hop were not statistically significant.

The CG highlighted differences statistically significant only in the 10 meters sprint $(4.53 \pm 1.038 \mathrm{sec}$ vs $3.99 \pm 1.17 \mathrm{sec}, p<0.05)$.

The main effect in test scores comparing the two groups (TG vs CG) at T1 was significant in the following tests: left limb Side hop ( $p<0.048$, ES: 0.54$)$, right limb Side hop $(p<0.039$, ES: 0.71$)$, left limb 6 meter timed hop $(p<0.006$, ES: $0.59)$, right limb 6 meter timed hop ( $p<0.005$, ES: 0.58$)$, vertical jump $(p<0.01$, ES: 0.59$)$, the $10 \times 5$ meters test $(p<0.036$, ES: 0.74$)$.

The results are summarized in Table 3 .

\section{Discussion}

The study aimed to verify the effects of an integrative training consisting of core stability exercises on the motor skills of prepubescent basketball players.

In the literature, there is only one study that investigated the relationships between core stability and jumping performance in young basketball players (Sannicandro \& Cofano, 2017).

The study was based on this previous research and implemented the load suggested by the authors limited to warm up.

The proposed supplementary program characterized the activation period of each lesson and provided for an increasing difficulty and intensity in the different lessons, going from tasks that required support in stability conditions, to tasks that required checking the trunk with the subject who made contact with tools that gave instability, as indicated in the literature (Räisänen et al., 2018;

Table 3. Results of TG and CG in the T0 and in the T1. Legend: 6MT: 6 meters timed hop; $\mathrm{p}^{\mathrm{a}}$ resulted from paired sample t-test; $P^{b}$ resulted from unpaired sample t-test; ES: Effect Size.

\begin{tabular}{|c|c|c|c|c|c|c|c|c|}
\hline & \multicolumn{2}{|c|}{ Training Group } & \multirow{2}{*}{$p^{\mathrm{a}}$} & \multicolumn{2}{|c|}{ Control Group } & \multirow{2}{*}{$p^{\mathrm{a}}$} & \multirow{2}{*}{$P^{b}$} & \multirow{2}{*}{$\mathrm{ES}(\delta)$} \\
\hline & T0 & $\mathrm{T} 1$ & & T0 & $\mathrm{T} 1$ & & & \\
\hline Side Hop left $(\mathrm{cm})$ & $37.80 \pm 6.327$ & $40.98 \pm 5.710$ & $0.026^{*}$ & $39.60 \pm 5.2$ & $39.93 \pm 4.69$ & 0.207 & $0.048^{*}$ & 0.54 \\
\hline Side Hop right $(\mathrm{cm})$ & $36.88 \pm 5.6$ & $41.92 \pm 6.9$ & $0.001^{\star *}$ & $39.40 \pm 6.8$ & $39.20 \pm 5.9$ & 0.068 & $0.039^{*}$ & 0.71 \\
\hline $6 \mathrm{MT}$ left (sec) & $5.65 \pm 0.55$ & $4.28 \pm 0.96$ & $0.000^{\star * *}$ & $5.447 \pm 0.36$ & $5.58 \pm 0.45$ & 0.126 & $0.006^{\star *}$ & 0.59 \\
\hline $6 \mathrm{MT}$ right (sec) & $5.45 \pm 0.75$ & $4.33 \pm 0.39$ & $0.000^{* * *}$ & $5.48 \pm 0.42$ & $5.44 \pm 0.59$ & 0.148 & $0.005^{\star *}$ & 0.58 \\
\hline Triple left $(\mathrm{cm})$ & $120.89 \pm 8.8$ & $124.12 \pm 6.9$ & 0.313 & $124.33 \pm 12.07$ & $125.41 \pm 13.09$ & 0.452 & 0.346 & 0.08 \\
\hline Triple right $(\mathrm{cm})$ & $118.87 \pm 15.43$ & $121.54 \pm 14.12$ & 0.360 & $122.43 \pm 10.23$ & $121.56 \pm 12.53$ & 0.373 & 0.469 & 0.08 \\
\hline Vertical jump (cm) & $13.22 \pm 3.6$ & $16.11 \pm 3.1$ & $0.004^{\star *}$ & $14.20 \pm 2.513$ & $14.96 \pm 3.8$ & 0.186 & $0.002^{* *}$ & 0.59 \\
\hline Sprint $10 \mathrm{~m}$ (sec) & $4.647 \pm 1.09$ & $3.887 \pm 1.11$ & $0.000^{* * *}$ & $4.53 \pm 1.038$ & $3.99 \pm 1.17$ & $0.043^{\star}$ & 0.118 & 0.22 \\
\hline Eurofit $10 \times 5 \mathrm{~m}(\mathrm{sec})$ & $33.66 \pm 3.15$ & $31.51 \pm 3.86$ & $0.001^{\star *}$ & $31.93 \pm 2.54$ & $34.69 \pm 2.98$ & 0.690 & $0.036^{*}$ & 0.74 \\
\hline
\end{tabular}

${ }^{*} p<0.05 ;{ }^{* *} p<0.01 ;{ }^{* *} p<0.0005$. 
Granacher et al., 2014; Prieske et al., 2015; Behm \& Anderson, 2006; Kibler et al., 2006; Hughes et al., 2017), even with the young (Gibbons \& Bird, 2019; Hutchinson et al., 2016).

The significant differences obtained in the pre-post test comparison in the TG characterized the monopodalic jump test, the vertical jump, the $6 \mathrm{~m}$ timed-hop test and the speed tests on the $10 \mathrm{~m}$ and $10 \times 5 \mathrm{~m}$. The jumping performance, with particular reference to those performed in monopodalic, as well as those of speed, are affected by the control of the trunk and pelvis, these districts that give stability to the extensor muscles of the lower limb and hip, assigned to jumping and at sprint (Lago-Fuentes et al., 2018; Hoshikawa et al., 2013; Afyon, 2014).

The CG, which used only specific sports exercises, in fact showed a decrease in 10 m-sprint performance $(p<0.043)$.

The results of the t-test between the two groups in the post test report significant statistically differences in the left and right side test (respectively, $\mathrm{p}>0.048$, ES: 0.54 and $p<0.039$, ES: 0.71 ), in the left and right $6 \mathrm{MT}$ (respectively, $p<$ 0.006, ES: 0.59 and $p<0.005$ ES: 0.58$)$, in the vertical jump $(p<0.002$, ES: 0.59$)$ and in the $10 \times 5 \mathrm{~m}$ test $(p<0.036$, ES: 0.74$)$.

This results confirming the effectiveness of the core stability exercises to influence the speed and jump tests and the ES value underlines its size (Lago-Fuentes et al., 2018; Ozmen, 2016; Hoshikawa et al., 2013; Afyon, 2014).

The results of this study are consistent and in line with similar studies that have described the effects of core district training on vertical jumping and sprinting performances in young soccer players (Ozmen, 2016; Hoshikawa et al., 2013; Afyon, 2014) in gymnastic (Durall et al., 2009), in professional female futsal players (Lago-Fuentes et al., 2018) or in young basketball players (Sannicandro \& Cofano, 2017).

The values identified in this study lead us to speculate that the core stability program, however, requires the introduction of further tasks in the warm up, if higher effect size values are to be obtained and in all assessment tests.

The study conducted, ultimately, confirms the need to hypothesize in youth sport supplementary sessions intended for strength training, as the literature has already suggested for several years (Faigenbaum et al., 1999; Faigenbaum et al., 2005; Emery et al., 2015; Larsen et al., 2016; Sannicandro \& Cofano, 2017; Kibler et al., 2006).

The prepubertal choice to practice a sport is, in fact, ever earlier: this orientation is justifiable only if it does not disregard the protection of the young practitioner health and the reduction of the injury risk from overload (Popkin et al., 2019; Rössler et al., 2016; Myer et al., 2015).

This study has some limitations: it made use of a heterogeneous sample of male and female children and did not detect the training age of each participant. Further studies should include whether males and females get the same benefits from this type of supplementary training. Likewise, it would be interesting to analyze whether the training age influence the final results. 


\section{Conclusion}

In conclusion, the sedentary increasing levels in young sports practitioners require careful consideration about the increasingly frequent introduction of core stability exercises. The staff must identify the training stage in which this type of exercise can be introduced without hindering technical training.

\section{Conflicts of Interest}

The authors declare no conflicts of interest regarding the publication of this paper.

\section{References}

Abenhaim, L., Rossignol, M., Valat, J. P., Nordin, M., Avouac, B., Blotman, F. et al. (2000). The Role of Activity in the Therapeutic Management of Back Pain. Report of the International Paris Task Force on Back Pain. Spine, 25, 1S-33S.

https://doi.org/10.1097/00007632-200002151-00001

Afyon, Y. A. (2014). Effect of Core Training on 16 Year-Old Soccer Payers. Educational Research and Reviews, 23, 1275-1279.

Akuthota, V., Ferreiro, A., Moore, T., \& Fredericson, M. (2008). Core Stability Exercise Principles. Current Sports Medicine Reports, 7, 39-44.

https://doi.org/10.1097/01.CSMR.0000308663.13278.69

Allen, B. A., Hannon, J. C., Burns, R. D., \& Williams, S. M. (2014). Effect of a Core Conditioning Intervention on Tests of Trunk Muscular Endurance in School-Aged Children. The Journal of Strength \& Conditioning Research, 28, 2063-2070. https://doi.org/10.1519/JSC.0000000000000352

Behm, D. G., \& Anderson, K. G. (2006). The Role of Instability with Resistance Training. The Journal of Strength \& Conditioning Research, 20, 716-722. https://doi.org/10.1519/00124278-200608000-00039

Bliven, K. C. H., \& Anderson, B. E. (2013). Core Stability Training for Injury Prevention. Sports Health, 6, 514-522. https://doi.org/10.1177/1941738113481200

Calatayud, J., Borreani, S., Martin, J., Martin, F., Flandez, J., \& Colado, J. C. (2015). Core Muscle Activity in a Series of Balance Exercises with Different Stability Conditions. Gait Posture, 42, 186-192. https://doi.org/10.1016/j.gaitpost.2015.05.008

Clark, D. R., Lambert, M. I., \& Hunter, A. M. (2018). Contemporary Perspectives of Core Stability Training for Dynamic Athletic Performance: A Survey of Athletes, Coaches, Sports Science and Sports Medicine Practitioners. Sports Medicine-Open, 4, 32. https://doi.org/10.1186/s40798-018-0150-3

Cohen, J. (1992). A Power Primer. Psychological Bulletin, 112, 155-159. https://doi.org/10.1037/0033-2909.112.1.155

Colella, D., Monacis, D., \& Massari, F. (2019). Assessment of Motor Performances in Italian Primary School Children: Results of SBAM Project. Advances in Physical Education, 9, 117-128. https://doi.org/10.4236/ape.2019.92009

Durall, C., Udermann, B., Johansen, D., Gibson, B., Reineke, D., \& Reuteman, P. (2009). The Effects of Preseason Trunk Muscle Training on Low-Back Pain Occurrence in Women Collegiate Gymnasts. The Journal of Strength \& Conditioning Research, 23, 86-92. https://doi.org/10.1519/JSC.0b013e31818b93ac

Emery, C. A., Roy, T. O., Whittaker, J. L., Nettel-Aguirre, A., \& van Mechelen, W. (2015). 
Neuromuscular Training Injury Prevention Strategies in Youth Sport: A Systematic Review and Meta-Analysis. British Journal of Sports Medicine, 49, 865-870. https://doi.org/10.1136/bjsports-2015-094639

Faigenbaum, A. D., Bellucci, M., Bernieri, A., Bakker, B., \& Hoorens, K. (2005). Acute Effects of Different Warm-Up Protocols on Fitness Performances in Children. The Journal of Strength \& Conditioning Research, 19, 376-381. https://doi.org/10.1519/00124278-200505000-00023

Faigenbaum, A. D., Westcott, W. L., Loud, R. L., \& Long, C. (1999). The Effects of Different Resistance Training Protocols on Muscular Strength and Endurance Development in Children. Pediatrics, 104, e5. https://doi.org/10.1542/peds.104.1.e5

Faries, M., \& Greenwood, M. (2007). Core Training: Stabilizing the Confusion. National Strength and Conditioning Association, 29, 10-25. https://doi.org/10.1519/00126548-200704000-00001

Gibbons, T. J., \& Bird, M. L. (2019). Exercising on Different Unstable Surfaces Increases Core Abdominal Muscle Thickness: An Observational Study Using Real-Time. Journal of Sport Rehabilitation, 1-6. https://doi.org/10.1123/jsr.2017-0385

Granacher, U., Schellbach, J., Klein, K., Prieske, O., Baeyens, J. P., \& Muehlbauer, T. (2014). Effects of Core Strength Training Using Stable versus Unstable Surfaces on Physical Fitness in Adolescents: A Randomized Controlled Trial. BMC Sports Science, Medicine and Rehabilitation, 6, 40. https://doi.org/10.1186/2052-1847-6-40

Heneghan, N. R., Lokhaug, S. M., Tyros, I., Longvastøl, S., \& Rushton, A. (2020). Clinical Reasoning Framework for Thoracic Spine Exercise Prescription in Sport: A Systematic Review and Narrative Synthesis. BMJ Open Sport \& Exercise Medicine, 6, e000713. https://doi.org/10.1136/bmjsem-2019-000713

Hibbs, A. E., Thompson, K. G., French, D., Wrigley, A., \& Spears, I. (2008). Optimizing Performance by Improving Core Stability and Core Strength. Sports Medicine, 38, 995-1008. https://doi.org/10.2165/00007256-200838120-00004

Hoshikawa, Y., Lida, T., Muramatsu, M., Li, N., Nakajima, Y., Chumank, K., \& Kanehisa, H. (2013). Effects of Stabilization Training on Trunk Muscularity and Physical Performances in Youth Soccer Players. The Journal of Strength \& Conditioning Research, 27, 3142-3149. https://doi.org/10.1519/JSC.0b013e31828bed36

Hughes, T., Sergeant, J. C., Parkes, M. J., \& Callaghan, M. J. (2017). Prognostic Factors for Specific Lower Extremity and Spinal Musculoskeletal Injuries Identified through Medical Screening and Training Load Monitoring in Professional Football (Soccer): A Systematic Review. BMJ Open Sport \& Exercise Medicine, 3, e000263.

https://doi.org/10.1136/bmjsem-2017-000263

Hutchinson, A. B., Yao, P., \& Hutchinson, M. R. (2016). Single-Leg Balance and Core Motor Control in Children: When Does the Risk for ACL Injury Occurs? BMJ Open Sport \& Exercise Medicine, 2, e000135. https://doi.org/10.1136/bmjsem-2016-000135

Jamison, S. T., Pan, X., \& Chaudhari, A. M. (2012). Knee Moments during Run-to-Cut Maneuvers Are Associated with Lateral Trunk Positioning. Journal of Biomechanics, 45, 1881-1885. https://doi.org/10.1016/j.jbiomech.2012.05.031

Kibler, W. B., Press, J., \& Sciascia, A. (2006). The Role of Core Stability in Athletic Function. Sports Medicine, 36, 189-198. https://doi.org/10.2165/00007256-200636030-00001

Kuligowski, T., Cieślik, B., Radziszewski, Ł., Czerwiński, B., \& Pióro, A. (2015). Body Somatic Type Influence on the Spinal Curvatures in Early Age School Children: Preliminary Report. Developmental Period Medicine, 19, 362-366.

Lago-Fuentes, C., Rey, E., Padrón-Cabo, A., Sal de Rellán-Guerra, A., Fragueiro-Rodríguez, A., \& García-Núñez, J. (2018). Effects of Core Strength Training Using Stable and Un- 
stable Surfaces on Physical Fitness and Functional Performance in Professional Female Futsal Players. Journal of Human Kinetics, 65, 213-224.

https://doi.org/10.2478/hukin-2018-0029

Larsen, L. R., Kristensen, P. L., Junge, T., Møller, S. F., Juul-Kristensen, B., \& Wedderkopp, N. (2016). Motor Performance as Risk Factor for Lower Extremity Injuries in Children. Medicine \& Science in Sports \& Exercise, 48, 1136-1143.

https://doi.org/10.1249/MSS.0000000000000877

Liebenson, C. (2011). Core Stability Training. Philadelphia, PA: Lippincott Williams \& Wilkins.

McGill, S. M. (2010). Core Training: Evidence Translating to Better Performance and Injury Prevention. Strength \& Conditioning Journal, 32, 33-46. https://doi.org/10.1519/SSC.0b013e3181df4521

Myer, G. D., Jayanthi, N., Difiori, J. P., Faigenbaum, A. D., Kiefer, A. W., Logerstedt, D., \& Micheli, L. J. (2015). Sport Specialization, Part I: Does Early Sports Specialization Increase Negative Outcomes and Reduce the Opportunity for Success in Young Athletes? Sports Health, 7, 437-442. https://doi.org/10.1177/1941738115598747

Ozmen, T. (2016). Relationship between Core Stability, Dynamic Balance and Jumping Performance in Soccer Players. Turkish Journal of Sport and Exercise, 18, 110-113.

Popkin, C. A., Bayomy, A. F., \& Ahmad, C. S. (2019). Early Sport Specialization. The Journal of the American Academy of Orthopaedic Surgeons, 27, e995-e1000. https://doi.org/10.5435/JAAOS-D-18-00187

Prieske, O., Muehlbauer, T., Borde, R., Gube, M., Bruhn, S., Behm, D. G., \& Granacher, U. (2015). Neuromuscular and Athletic Performance Following Core Strength Training in Elite Youth Soccer: Role of Instability. Scandinavian Journal of Medicine \& Science in Sports, 26, 48-56. https://doi.org/10.1111/sms.12403

Räisänen, A. M., Pasanen, K., Krosshaug, T., Vasankari, T., Kannus, P., Heinonen, A. et al. (2018). Association between Frontal Plane Knee Control and Lower Extremity Injuries: A Prospective Study on Young Team Sport Athletes. BMJ Open Sport \& Exercise Medicine, 4, e000311. https://doi.org/10.1136/bmjsem-2017-000311

Reed, C. A., Ford, K. R., Myer, G. D., \& Hewett, T. E. (2012). The Effects of Isolated and Integrated "Core Stability" Training on Athletic Performance Measures. A Systematic Review. Sports Medicine, 42, 697-706. https://doi.org/10.1007/BF03262289

Rössler, R., Junge, A., Chomiak, J., Dvorak, J., \& Faude, O. (2016). Soccer Injuries in Players Aged 7 to 12 Years: A Descriptive Epidemiological Study over 2 Seasons. The American Journal of Sports Medicine, 44, 309-317. https://doi.org/10.1177/0363546515614816

Saeterbakken, A. H., van den Tillaar, R., \& Seiler, S. (2011). Effect of Core Stability Training on Throwing Velocity in Female Handball Players. The Journal of Strength \& Conditioning Research, 25, 712-718. https://doi.org/10.1519/JSC.0b013e3181cc227e

Sannicandro, I. (2014). L'allenamento del core nella prevenzione e nella performance, Nonsolofitness Editor, Castello d'Argile (BO).

Sannicandro, I., \& Cofano, G. (2017). Core Stability Training and Jump Performance in Young Basketball Players. International Journal of Science and Research (IJSR), 6, 479-482.

Sasaki, S., Tsuda, E., Yamamoto, Y., Maeda, S., Kimura, Y., Fujita, Y., \& Ishibashi, Y. (2019). Core-Muscle Training and Neuromuscular Control of the Lower Limb and Trunk. Journal of Athletic Training, 54, 959-969.

https://doi.org/10.4085/1062-6050-113-17 
Sato, K., \& Mokha, M. (2009). Does Core Strength Training Influence Running Kinetics, Lower-Extremity Stability, and 5000-m Performance in Runners? The Journal of Strength \& Conditioning Research, 23, 133-140. https://doi.org/10.1519/JSC.0b013e31818eb0c5

Sharrock, C., Cropper, J., Mostad, J., Johnson, M., \& Malone, T. (2011). A Pilot Study of Core Stability and Athletic Performance: Is There a Relationship? International Journal of Sports Physical Therapy, 6, 63-74.

Shinkle, J., Nesser, T. W., Demchak, T. J., \& McMannus, D. M. (2012). Effect of Core Strength on the Measure of Power in the Extremities. The Journal of Strength \& Conditioning Research, 26, 373-380. https://doi.org/10.1519/JSC.0b013e31822600e5

Weedon, B. D., Liu, F., Mahmoud, W., Metz, R., Beunder, K., Delextrat, A. et al. (2018). The Relationship of Gross Upper and Lower Limb Motor Competence to Measures of Health and Fitness in Adolescents Aged 13-14 Years. BMJ Open Sport \& Exercise Medicine, 4, e000288. https://doi.org/10.1136/bmjsem-2017-000288

Willardson, J. M. (2007). Core Stability Training: Applications to Sports Conditioning Programs. The Journal of Strength \& Conditioning Research, 21, 979-985. https://doi.org/10.1519/00124278-200708000-00054

Wirth, K., Hartmann, H., Mickel, C., Szilvas, E., Keiner, M., \& Sander, A. (2017). Core Stability in Athletes: A Critical Analysis of Current Guidelines. Sports Medicine, 47, 401-414. https://doi.org/10.1007/s40279-016-0597-7

Wu, X. Y., Han, L. H., Zhang, J. H., Luo, S., Hu, J. W., \& Sun, K. (2017). The Influence of Physical Activity, Sedentary Behavior on Health-Related Quality of Life among the General Population of Children and Adolescents: A Systematic Review. PLoS ONE, 12, e0187668. https://doi.org/10.1371/journal.pone.0187668 